\title{
Comparison of treatment patterns in schizophrenia between China and J apan (2001-2009)
}

\section{Running Head: Treatment in schizophrenia}

Yu-Tao Xiang, MD, PhD ${ }^{1 \#^{*}}$,

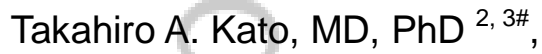

Taishiro Kishimoto, MD, PhD ${ }^{4 \#}$,

Gabor S. Ungvari, MD, $\mathrm{PhD}^{5,6}$,

Helen F.K. Chiu, FRCPsych ${ }^{7}$,

Tian-Mei Si, MD, $\mathrm{PhD}^{8}$,

Shu-Yu Yang, $\mathrm{PhD}^{9}$,

Senta Fujii, MD, PhD ${ }^{10}$,

Chee H. Ng, MD ${ }^{11}$

Naotaka Shinfuku, MD, PhD ${ }^{12}$

1. Unit of Psychiatry, Faculty of Health Sciences, University of Macau, Macao SAR, China;

2. Department of Neuropsychiatry, Graduate School of Medical Sciences, Kyushu University, Fukuoka, Japan;

3. Innovation Center for Medical Redox Navigation, Kyushu University, Fukuoka, Japan

4. Keio University School of Medicine, Tokyo, Japan;

5. School of Psychiatry and Clinical Neurosciences, University of Western Australia, Perth, Australia;

6. School of Psychiatry \& Clinical Neurosciences, University of Western Australia, Perth, Australia;

7. Department of Psychiatry, Chinese University of Hong Kong, Hong Kong SAR, China;

8. The National Clinical Research Center for Mental Disorders (Peking University Sixth Hospital) \& Peking University Institute of Mental Health \& The Key Laboratory of Mental Health, Ministry of Health (Peking University), Beijing, China;

9. Department of Pharmacy, Taipei City Hospital, Taipei, Taiwan;

10. Department of Disaster Psychiatry, Fukushima Medical University, Fukushima, Japan;

11. Department of Psychiatry, University of Melbourne, Melbourne, Victoria, Australia;

12. International Center for Medical Research, Kobe University School of Medicine, Kobe, Japan

\# These authors contributed equally to this work.

*Address correspondence to Dr. Yu-Tao Xiang, 3/F, Building E12, Faculty of Health Sciences, University of Macau, Avenida da Universidade, Taipa, Macau SAR, China. Fax: +853-2288-2314;

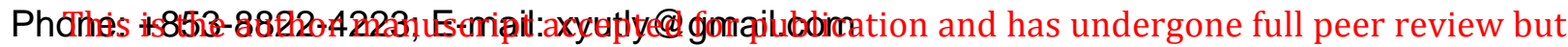
has not been through the copyediting, typesetting, pagination and proofreading process, which may lead to differences between this version and the Version of Record. Please cite this article as doi: 10.1111/appy.12277 


\section{Acknowledgements}

This study was supported by the University of Macau (SRG2014-00019-FHS; MYRG2015-00230-FHS; MYRG2016-00005-FHS), the Institute of Mental Health Research Grant (CRC 249/2008) in Singapore, and the Taiwan Bureau of National Health Insurance (DOH92-NH-1025), Chang Gung Memorial Hospital (CMRPG83043) and the Taipei City Government (97001-62-010) in Taiwan. The authors are grateful to all clinicians involved in the REAP project.

\section{Disclosure statement}

There is no conflict of interest concerning the authors in conducting this study and preparing the manuscript. 
Comparison of treatment patterns in schizophrenia between China and Japan (2001-2009)

Running Head: Treatment in schizophrenia 


\section{Abstract}

Introduction: To date no study has compared the treatment patterns for schizophrenia specifically between China and Japan. This study examined the cross-national differences in the use of psychotropic drugs and electroconvulsive therapy (ECT) in schizophrenia.

Method: Data on 3,248 schizophrenia inpatients $(n=1524$ in China and $n=1724$ in Japan) were collected by either chart review or interviews during designated study periods between 2001 and 2009. Patients' socio-demographic and clinical characteristics, prescriptions of psychotropic drugs and ECT use were recorded using a standardized protocol and data collection procedure.

Results: Multivariate analyses revealed that compared to their Japanese counterparts, Chinese inpatients had a shorter length of current hospitalization, were significantly less frequently prescribed SGAs (except clozapine), antipsychotic polypharmacy, benzodiazepines and mood stabilizers, and more likely to receive clozapine, antidepressants and ECT.

Conclusions: Substantial variations in inpatient treatment patterns for schizophrenia were found between China and Japan. The common use of ECT and clozapine in Chinese inpatients and the frequent use of antipsychotic polypharmacy and high antipsychotic doses in Japanese inpatients need to be addressed.

Key words: China, ethnicity, Japan, prescription, schizophrenia 


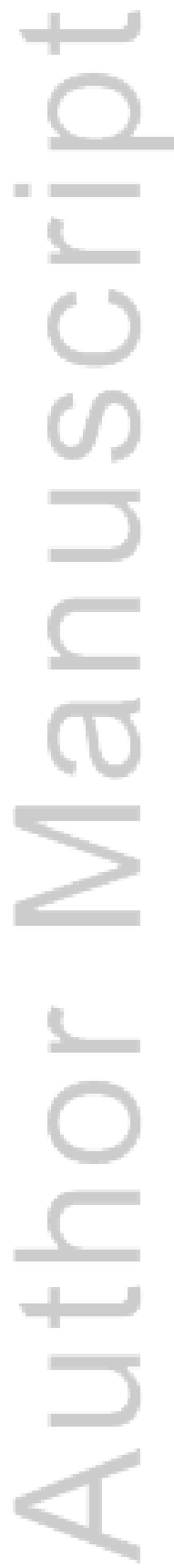

This article is protected by copyright. All rights reserved. 


\section{Introduction}

Over the past decades, the impact of ethnicity, culture and clinical practice on prescribing patterns of psychotropic drugs for schizophrenia has been intensively investigated (Opolka et al., 2004; Wheeler et al., 2008). Although the prevalence of schizophrenia seems to be independent of ethnicity (Robins et al., 1984; Xiang et al., 2008), clinical, cultural and systemic factors can affect its treatment and patterns of psychotropic drug prescription (Kuno and Rothbard, 2002; Opolka et al., 2003; Opolka et al, 2004; Udomratn and Ng, 2008; Wheeler et al, 2008).

Most recent studies on ethno-cultural differences in psychotropic prescription patterns in schizophrenia have been conducted in Western settings. For instance, African American patients were found to be significantly less likely to receive second-generation antipsychotics (SGAs) and antidepressants, but were prescribed higher doses of antipsychotics and depot antipsychotics than their Caucasian counterparts (Citrome et al., 1996; Lehman and Steinwachs, 1998; Van Dorn et al., 2005).

China and J apan are the two most populous countries in East Asia which have undergone rapid economic development. However both countries have considerable differences in sociocultural context, health system and clinical practice, which may impact on treatment prescription patterns. The aim of this study was to compare the differences in treatment patterns for schizophrenia inpatients between China and Japan. The study focused on inpatients because in East Asia a large number of schizophrenia patients are treated in psychiatric 
hospitals for long periods as community care is in its infancy (Shinfuku and Tan, 2008).

\section{Methods}

Settings, study design and subjects

The study was part of the Research in East Asia on Psychotropic Prescription (REAP) project which is a pharmaco-epidemiological survey on prescription trends of psychotropic drugs in schizophrenia inpatients in East Asia including mainland China (in the following: China), Hong Kong, Japan, Korea, Singapore and Taiwan using a standardized protocol and data collection procedure. Centers in India, Malaysia and Thailand joined the surveys in 2009. The three REAP surveys were conducted in July 2001, July 2004, and October 2008-March 2009. Consensus meetings to discuss data collection were held prior to each survey. Participating patients had to fulfill the following entry criteria: (1) diagnosis of schizophrenia according to either ICD-10 or DSM-IV; (2) ability to comprehend the aims of the study if interviewed. Patients with clinically significant medical conditions were excluded. Doses of antipsychotics were converted into chlorpromazine equivalent milligrams (CPZeq) (APA, 1997; Kane et al., 1998; Woods, 2003). In this study the data collected from China and Japan were included for analyses.

Eligible patients were examined consecutively at each site. Socio-demographic and clinical characteristics including age, sex, type of current 
antipsychotics, benzodiazepines, mood stabilizers, antidepressants, prominent positive (delusions and hallucinations) and negative symptoms (affective flattening, alogia, and avolition) in the past month, use of ECT during the census period and acute extrapyramidal side effects (EPS including rigidity, akinesia, tremor, akathisia, dystonia and tardive dyskinesia) were collected using a form designed for the study. Data were collected by a review of medical records in 2001 and by either a review of medical records only or a review supplemented by a clinical interview in both 2004 and 2009 by the attending psychiatrists or members of the research team with the agreement of the treating psychiatrist.

The study focused on eight major groups or aspects of treatments viz. SGA except clozapine, clozapine, antipsychotic polypharmacy, benzodiazepines, mood stabilizer, antidepressants, high dose antipsychotics $(>/=1000 \mathrm{mg} / \mathrm{d}$ in CPZeq) and electroconvulsive therapy. Clozapine was singled out due to its special place in the use of treatment-refractory patients. Antipsychotic polypharmacy was defined as the concurrent use of more than one antipsychotic drug.

The study was approved by the clinical research ethics committees of the respective centers. Given the anonymous nature of the retrospective chart review and the minimal risk to patients, informed consent was waived at some study sites provided that only the medical records were reviewed in line with local ethical standards (Shinfuku and Tan, 2008). All patients who were interviewed provided written or verbal consent according to the requirements of the 
respective clinical research ethics committees.

Statistical analysis

The data were analyzed using SPSS 20.0 for Windows. The comparisons between Chinese and Japanese patients with respect to socio-demographic and clinical characteristics were performed using independent sample t-test, Mann-Whitney $\mathrm{U}$ test, and chi-square test, as appropriate. Analysis of covariance (ANCOVA) was used to adjust for relevant demographic and clinical covariates and to compare the length of the current hospitalization. Multiple logistic regression analysis with the "Enter" method was used to adjust for the relevant demographic and clinical covariates and to determine the independent contribution of Chinese versus J apanese patient groups on prescription patterns and use of ECT. The one-sample Kolmogorov-Smirnov test was used to check the normality of distribution for continuous variables. The level of significance was set at 0.05 (two-tailed).

\section{Results}

In China, four major psychiatric hospitals participated in the three surveys involving altogether 1,524 patients: 611 in 2001, 504 in 2004, and 409 in 2009. In Japan, 10 major hospitals were involved in 2001, 10 in 2004 and 8 in 2009, including altogether 1,724 patients: 627 in 2001, 583 in 2004 and 514 in 2009.

Table 1 shows the socio-demographic and clinical characteristics separately for Chinese and Japanese patients. Chinese patients were significantly younger, had shorter length of hospitalization, and more likely to be in their first hospital 
admission. They also had less prominent positive and negative symptoms, less acute EPS and tardive dyskinesia, lower dose of antipsychotics, less likely to be prescribed SGAs (except clozapine), antipsychotic polypharmacy, benzodiazepines and mood stabilizers, and more likely to be prescribed clozapine, antidepressants and ECT.

After controlling for the confounding effects of study time, age, first admission, psychopathology, acute EPS and tardive dyskinesia by ANCOVA, the length of current hospitalization was still significantly longer in Japanese patients than their Chinese counterparts $\left(F_{(8,3247)}=151.3, p<0.001\right)$. In stepwise multiple logistic regression analyses, study time, age, first admission, psychopathology, acute EPS and tardive dyskinesia were controlled for. Compared to Japanese patients, Chinese patients were significantly less frequently prescribed SGAS (other than clozapine), antipsychotic polypharmacy, benzodiazepines and mood stabilizers, and more likely to receive clozapine, antidepressants and ECT (Table 2).

\section{Discussion}

According to the WHO report in 2011 (World Health Organization, 2011), there were 1,354 million population in China, with 1.5 psychiatrists and 1.5 psychiatric beds per 10,000 population. In Japan, there were 127 million population, with 10.1 psychiatrists and 27.7 psychiatric beds per 10,000 population. In the past decades, developing community-based mental health services has been 
encouraged in both China and Japan, but due to historical and sociocultural reasons, a large number of psychiatric patients have continued to receive hospital-based services (Shinfuku and Tan, 2008). In this study the length of current hospitalization in Japan had been decreasing over time ( 540.5 days in 2001, 411.8 days in 2004 and 373.2 days in 2009), but was still significantly longer than that in China. This could be explained by the fact that J apan had one of the largest number of psychiatric beds and psychiatrists per capita ( $\mathrm{Ng}$ et al., 2010) and the tradition of providing long-term hospital-based treatment for schizophrenia. It was reported that around $80 \%$ of patients who stayed over 10 years in psychiatric hospitals in Japan had a diagnosis of schizophrenia (Shinfuku, 2012). In addition, all patients receiving psychiatric care in both private and public psychiatric hospitals are covered by national insurance system. Patients need to pay $10 \%-30 \%$ of their treatment costs and the rest is compensated by public funds. Long stay in private and public psychiatric hospitals may be subsided by the life protection scheme, therefore exempting patient's payments. This medical compensation system has contributed significantly to the long-term hospitalization. The decrease in length of hospitalization may be attributed to the treatment financial point system in J apan by which the authority could shape the health service system. To discourage long hospital stay in past two decades, the J apanese government has decreased financial incentive for inpatient care, which could contribute to the decreasing trend of hospitalization length (Shinfuku, 1998). 
Clozapine is arguably the most effective antipsychotic medication and the last-resort for treatment-resistant schizophrenia (O'Brien, 2004). Over one third of the Chinese patients were taking clozapine, which is considerably higher than the findings reported for Caucasian patients. For example, only $1 \%$ of schizophrenia patients in the American Veterans Administration in New York received clozapine in 2002 (Weissman, 2002). The corresponding figure in a Canadian sample was 6.7\% (Latimer et al., 2013). The Danish National Register showed that the proportion of schizophrenia patients on clozapine changed only slightly, from $9.0 \%$ in 1996 to $10.1 \%$ by 2007 (Nielsen et al., 2012). In China, the official treatment guidelines for the prevention and treatment of psychiatric disorders recommend that clozapine should be considered only after first-generation antipsychotics or other second-generation antipsychotics have been deemed ineffective after 6-8 weeks of treatment; blood monitoring for patients on clozapine weekly or biweekly during the first 6 months and biweekly or monthly afterwards is mandatory (Chinese Medical Association, 2003).

There are differences in drug usage patterns across countries and regions that may result from systemic, health cost and cross-cultural factors. In the case of clozapine, this drug was introduced in China in 1976, and remained frequently used despite being discontinued in the rest of the developed world. Over the past three decades clozapine has become the most frequently administered antipsychotic drug in China resulting in extensive clinical and research experience (Liu and Li, 2003; Zhang and Wang, 2001). In contrast, clozapine had 
not been available in Japan during the study period until late 2009. Second, the cost of clozapine treatment may have also contributed to its extensive use in China. It has been the cheapest atypical antipsychotic drug (US\$ 0.08 for $300 \mathrm{mg}$ ), multiple times less than in neighboring countries in the East Asian region (Xiang et al., 2007b).

In this study, Chinese patients were markedly less likely to be receiving SGAs except clozapine than J apanese patients. Various factors including clinician skills, drug knowledge and preference, patients' attitude, the culturally determined patient-clinician relationship, drug costs, insurance coverage and health care policy could play an important role in prescribing SGAs (Xiang et al, 2007b). In China, for example, only clozapine and risperidone were covered by basic health care insurance before 2005, thus other SGAs could not be prescribed unless they were paid for by the patients (Xiang et al, 2007b).

Antipsychotic polypharmacy is common in clinical practice (Faries et al., 2005) although treatment guidelines only recommended it as a last option in the treatment of schizophrenia (Suppes et al., 2005). The frequency of antipsychotic polypharmacy of $27.6 \%$ found in China and $69.4 \%$ in Japan are higher than the frequencies found in the pooling data from 147 studies in North America (16.0\%) and Europe (23.0\%) (Gallego et al., 2012a). The frequency of high antipsychotic doses was $8.7 \%$ in Chinese patients, while the corresponding figure was $23.5 \%$ in Japanese patients. It was reported that local clinical prescribing practices may play an important contribution to the frequent use of antipsychotic polypharmacy 
and high antipsychotic doses in Japan (Gallego et al, 2012a; Kishimoto et al., 2013), especially when patients were symptomatic. However, treating psychiatrists seldom reduced the doses and number of antipsychotics even when patients were clinically stabilized. Moreover, it has been reported that sometimes sedation was the primary purpose of pharmacotherapy for schizophrenia inpatients in Japan (Fujii and Shinfuku, 2005; Shinfuku and Tan, 2008), which may also explain these findings.

It should be noted that antipsychotic polypharmacy is associated with increased hospitalization rates, increased side effects, and higher treatment cost and increased mortality (Elie et al., 2010; Gallego et al., 2012b; Tiihonen et al., 2012). In addition, high antipsychotic doses may increase the risk of extrapyramidal side effects (Pierre, 2005) and hyperprolactinemia (Byerly et al., 2007). Based on these findings, several attempts have been made to reduce antipsychotic polypharmacy and high antipsychotic doses in clinical practice settings (Essock et al., 2011; Tani et al., 2013; Xiang et al., 2014).

To alleviate affective and negative symptoms, antidepressants are often used in schizophrenia with only limited evidence supporting this practice (Conley et al., 2007; Sepehry et al., 2007). Augmentation of antipsychotic treatment with antidepressants increases the likelihood of adverse drug-drug interactions because of the effects of antidepressants on the cytochrome P450 (Mojtabai and Olfson, 2010; Nemeroff et al., 1996). More Chinese patients were prescribed antidepressants in this sample. Since depressive symptoms were not measured 
in this study, their potentially confounding effects could not be controlled for.

Mood stabilizers and benzodiazepines are frequently prescribed as adjunctive medications with antipsychotic treatment in schizophrenia. We found that around one third and one fourth of Japanese patients received mood stabilizers and benzodiazepines, respectively, both higher than in Chinese patients. The reasons behind this practice is that mood stabilizers may help control aggression and irritability and augment antipsychotics (Citrome, 1995) for patients who do not, or only partially respond to antipsychotic treatment (Parepally et al., 2002). Benzodiazepines are prescribed primarily for anxiety, insomnia and as part of rapid tranquillization aiming to control psychotic symptoms and agitation (Tor et al., 2011; Xiang et al., 2007a). However, there is lack of solid evidence to support these adjunctive medications (Buchanan et al., 2010; Chen et al., 2007). Negatively, concurrent use of mood stabilizers and benzodiazepines may increase the risk of side effects, the cost of treatment and reduce treatment adherence (Parepally et al, 2002).

In this study $10.1 \%$ of Chinese patients received ECT with an increasing trend $(5.9 \%$ in $2001,11.1 \%$ in 2004 and $15.2 \%$ in 2009), while the figure was only $0.8 \%$ in Japan. The clinical decision to administer ECT is affected by its perceived efficacy, side effects and costs, local clinical practice and treatment guidelines. In China, ECT is usually recommended for the treatment of mood disorders and schizophrenia, particularly for those with suicidal or aggressive behavior and catatonia (Chinese Medical Association, 2003; Shen, 2009). In 
addition, socio-cultural and historical factors are also related to treatment decisions. In China, psychiatrists have performed unmodified ECT for decades with little controversy between the 1950s and 1970s due to the lack of links to the international psychiatric communities (Leung et al., 2009). With the refined techniques and expertise, side effects and complications associated with ECT have been minimized. All these factors may account for the common use of ECT (Wang et al., 2014). Modified ECT started to replace unmodified ECT gradually since the early-mid-2000s. Only unmodified ECT was used in the four participating hospitals in China in the 2001 survey, but in the 2004 and 2009 surveys only modified ECT was used. Each ECT course comprised 6-12 sessions for adult patients aged between 18 and 59 years under general anesthesia.

The increasing trend of ECT use in China may be explained by the two reasons. Compared to unmodified ECT, modified ECT less likely causes muscle pain, headache and body aches, making it more acceptable by patients and their families, which, in turn, may increase its use. Moreover, the national community psychiatric services started to be established in China (Xiang et al., 2012), therefore the health authority required psychiatric hospitals to shorten length of hospitalization. Therefore, ECT has been more widely used for hospitalized patients to shorten hospital stays (Cong et al., 2006; Huang et al., 2010).

The major strengths of this study include the large sample size. However, the results should be interpreted with caution because of several methodological limitations. First, the range of important variables was omitted, for example, 
co-morbid substance use might have influenced prescribing patterns. Second, pharmacogenetic differences between ethnic groups could play a role on prescription, particularly CYP1A2, a member of the cytochrome P450 superfamily (CYPs), which is involved in the metabolism of clozapine (Grant et al., 1983). This study, however, did not include pharmacogenetic testing due to logistical reasons. Third, no standardized assessment for psychopathology and drug-induced side effects were employed. Fourth, due to logistical reasons, the participating hospitals were not randomly selected. Furthermore, in this pharmaco-epidemiological study with three separate samples, a small proportion of patients might be repeatedly assessed, although the wide time span between the three surveys minimized this possibility. Fifth, the data were collected by a chart review in 2001, and by either a review of case chart or patient interviews in 2004 and 2009, which might have led to observational bias. Finally, inpatients were involved in the REAP surveys hence the results cannot be applied to outpatients.

In conclusion, there are significant differences in antipsychotic prescription and use of ECT between Chinese and Japanese schizophrenia inpatients. Determining the reasons behind the differences between the two countries in future studies will be an important contribution to optimizing pharmacotherapy for schizophrenia. 


\section{References}

APA, 1997. Practice Guideline for the Treatment of Patients with Schizophrenia. Washington, DC: American Psychiatric Press.

Buchanan R.W., Kreyenbuhl, J., Kelly, D.L., Noel, J.M., Boggs, D.L., Fischer, B.A., Himelhoch, S., Fang, B., Peterson, E., Aquino, P.R., Keller, W. (2010) The 2009 schizophrenia PORT psychopharmacological treatment recommendations and summary statements. Schizophrenia Bulletin, 36, 71-93.

Byerly M., Suppes, T., Tran, Q.V., Baker, R.A. (2007) Clinical implications of antipsychotic-induced hyperprolactinemia in patients with schizophrenia spectrum or bipolar spectrum disorders: recent developments and current perspectives. J ournal of Clinical Psychopharmacology, 27, 639-661.

Chen H., Kennedy, W.K., Dorfman, J.H., Fincham, J.E., Reeves, J., Martin, B.C. (2007) The effect of adjunctive mood stabilizers on antipsychotic utilization pattern and health resource utilization for Medicaid enrollees with schizophrenia. Current Medical Research and Opinion, 23, 1351-1365.

Chinese Medical Association, 2003. Guideline for the Prevention and Treatment of Psychiatric Disorders in China. Beijing: Chinese Medical Association.

Citrome L. (1995) Use of lithium, carbamazepine, and valproic acid in a state-operated psychiatric hospital. Journal of Pharmacy Technology, 11, $55-59$.

Citrome L., Levine, J., Allingham, B. (1996) Utilization of depot neuroleptic 
medication in psychiatric inpatients. Psychopharmacology Bulletin, 32, $321-326$.

Cong W.D., Zou, X.F., Yan, S.Y. (2006) Analysis of effect and cost of modified ECT for schizophrenia (in Chinese). Journal of Clinical Psychological Medicine, $16,56-57$.

Conley R.R., Ascher-Svanum, H., Zhu, B., Faries, D.E., Kinon, B.J. (2007) The burden of depressive symptoms in the long-term treatment of patients with schizophrenia. Schizophrenia Research, 90, 186-197.

Elie D., Poirier, M., Chianetta, J., Durand, M., Gregoire, C., Grignon, S. (2010) Cognitive effects of antipsychotic dosage and polypharmacy: a study with the BACS in patients with schizophrenia and schizoaffective disorder. J Psychopharmacol, 24, 1037-1044.

Essock S.M., Schooler, N.R., Stroup, T.S., McEvoy, J.P., Rojas, I., Jackson, C., Covell, N.H. (2011) Effectiveness of Switching From Antipsychotic Polypharmacy to Monotherapy. American Journal of Psychiatry, 168, 702-708.

Faries D., Ascher-Svanum, H., Zhu, B., Correll, C., Kane, J. (2005) Antipsychotic monotherapy and polypharmacy in the naturalistic treatment of schizophrenia with atypical antipsychotics. BMC Psychiatry, 5, 26.

Fujii S., Shinfuku, N. (2005) Utilization of levomepromazine in Japan - Its role as an antipsychotic in psychiatric pharmacotherapy (In Japanese). Rinsyo Seisin Yakuri, 8, 1227-1238. 
Gallego J.A., Bonetti, J., Zhang, J., Kane, J.M., Correll, C.U. (2012a) Prevalence and correlates of antipsychotic polypharmacy: a systematic review and meta-regression of global and regional trends from the 1970s to 2009 . Schizophrenia Research, 138, 18-28.

Gallego J.A., Nielsen, J., De Hert, M., Kane, J.M., Correll, C.U. (2012b) Safety and tolerability of antipsychotic polypharmacy. Expert Opin Drug Saf, 11, 527-542.

Grant D.M., Tang, B.K., Kalow, W. (1983) Variability in caffeine metabolism. Clinical Pharmacology and Therapeutics, 33, 591-602.

Huang J., Gao, Y.X., Liu, D.F. (2010) Modified electroconvulsive therapy for bipolar disorders (in Chinese). Journal of Clinical Psychological Medicine, $20,57$.

Kane J.M., Aguglia, E., Altamura, A.C., Ayuso Gutierrez, J.L., Brunello, N., Fleischhacker, W.W., Gaebel, W., Gerlach, J., Guelfi, J.D., Kissling, W., Lapierre, Y.D., Lindstrom, E., Mendlewicz, J., Racagni, G., Carulla, L.S., Schooler, N.R. (1998) Guidelines for depot antipsychotic treatment in schizophrenia. European Neuropsychopharmacology Consensus Conference in Siena, I taly. European Neuropsychopharmacology, 8, 55-66. Kishimoto T., Watanabe, K., Uchida, H., Mimura, M., Kane, J.M., Correll, C.U. (2013) Antipsychotic polypharmacy: A Japanese survey of prescribers' attitudes and rationales. Psychiatry Research. ???

Kuno E., Rothbard, A.B. (2002) Racial disparities in antipsychotic prescription 
patterns for patients with schizophrenia. American Journal of Psychiatry, 159, 567-572.

Latimer E., Wynant, W., Clark, R., Malla, A., Moodie, E., Tamblyn, R., Naidu, A.

(2013) Underprescribing of clozapine and unexplained variation in use across hospitals and regions in the Canadian province of Quebec. Clin Schizophr Relat Psychoses, 7, 33-41.

Lehman A.F., Steinwachs, D.M. (1998) Patterns of usual care for schizophrenia: initial results from the Schizophrenia Patient Outcomes Research Team (PORT) Client Survey. Schizophrenia Bulletin, 24, 11-20; discussion 20-32. Leung C.M., Xiang, Y.T., He, J.L., Xu, H.L., Ma, L., Fok, M.L., Ungvari, G.S. (2009) Modified and unmodified electroconvulsive therapy: a comparison of attitudes between psychiatrists in Beijing and Hong Kong. Journal of ECT, $25,80-84$

Liu T.L., Li, C.Y. (2003) The comparison of use of antipsychotics in first-episode patients with schizophrenia (in Chinese). Medical journal of Chinese People Health, 15, 289-290.

Mojtabai R., Olfson, M. (2010) National trends in psychotropic medication polypharmacy in office-based psychiatry. Archives of General Psychiatry, $67,26-36$.

Nemeroff C.B., DeVane, C.L., Pollock, B.G. (1996) Newer antidepressants and the cytochrome P450 system. American J ournal of Psychiatry, 153, 311-320.

Ng C., Setoya, Y., Koyama, A., Takeshima, T. (2010) The ongoing development of 
community mental health services in Japan: utilizing strengths and opportunities. Australasian Psychiatry, 18, 57-62.

Nielsen J., Roge, R., Schjerning, O., Sorensen, H.J., Taylor, D. (2012) Geographical and temporal variations in clozapine prescription for schizophrenia. European Neuropsychopharmacology, 22, 818-824.

O'Brien A. (2004) Starting clozapine in the community: a UK perspective. CNS Drugs, $18,845-852$.

Opolka J.L., Rascati, K.L., Brown, C.M., Barner, J.C., J ohnsrud, M.T., Gibson, P.J . (2003) Ethnic differences in use of antipsychotic medication among Texas medicaid clients with schizophrenia. Journal of Clinical Psychiatry, 64, 635-639.

Opolka J.L., Rascati, K.L., Brown, C.M., Gibson, P.J. (2004) Ethnicity and prescription patterns for haloperidol, risperidone, and olanzapine. Psychiatric Services, 55, 151-156.

Parepally H., Chakravorty, S., Levine, J., Brar, J.S., Patel, A.M., Baird, J.W., Chalasani, L., Delaney, J.A., Atzert, R., Chengappa, K.N. (2002) The use of concomitant medications in psychiatric inpatients treated with either olanzapine or other antipsychotic agents: a naturalistic study at a state psychiatric hospital. Progress in Neuro-Psychopharmacology and Biological Psychiatry, 26, 437-440.

Pierre J.M. (2005) Extrapyramidal symptoms with atypical antipsychotics : incidence, prevention and management. Drug Safety, 28, 191-208. 
Robins L.N., Helzer, J.E., Weissman, M.M., Orvaschel, H., Gruenberg, E., Burke, J.D., Jr., Regier, D.A. (1984) Lifetime prevalence of specific psychiatric disorders in three sites. Archives of General Psychiatry, 41, 949-958.

Sepehry A.A., Potvin, S., Elie, R., Stip, E. (2007) Selective serotonin reuptake inhibitor (SSRI) add-on therapy for the negative symptoms of schizophrenia: a meta-analysis. Journal of Clinical Psychiatry, 68, 604-610.

Shen Y.C., 2009. Psychiatry. Beijing: People's Medical Publishing House.

Shinfuku N. (1998) Mental health services in Asia: international perspective and challenge for the coming years. Psychiatry and Clinical Neurosciences, 52, 269-274.

Shinfuku N. (2012) What are happening i nthe mental health system in Japan: Some observations. Taiwanese J ournal of Psychiatry, 26, 70-76.

Shinfuku N., Tan, C.H. (2008) Pharmacotherapy for schizophrenic inpatients in East Asia--changes and challenges. Int Rev Psychiatry, 20, 460-468.

Suppes T., Dennehy, E.B., Hirschfeld, R.M., Altshuler, L.L., Bowden, C.L., Calabrese, J.R., Crismon, M.L., Ketter, T.A., Sachs, G.S., Swann, A.C. (2005) The Texas implementation of medication algorithms: update to the algorithms for treatment of bipolar I disorder. J ournal of Clinical Psychiatry, $66,870-886$.

Tani H., Uchida, H., Suzuki, T., Fujii, Y., Mimura, M. (2013) Interventions to reduce antipsychotic polypharmacy: a systematic review. Schizophrenia 
Research, 143, 215-220.

Tiihonen J., Suokas, J.T., Suvisaari, J.M., Haukka, J., Korhonen, P. (2012) Polypharmacy with antipsychotics, antidepressants, or benzodiazepines and mortality in schizophrenia. Archives of General Psychiatry, 69, 476-483.

Tor P.C., Ng, T.P., Yong, K.H., Sim, K., Xiang, Y.T., Wang, C.Y., Lee, E.H., Fujii, S., Yang, S.Y., Chong, M.Y., Ungvari, G.S., Si, T., He, Y.L., Chung, E.K., Chee, K.Y., Trivedi, J., Udomratn, P., Shinfuku, N., Kua, E.H., Tan, C.H., Sartorius, N., Baldessarini, R.J. (2011) Adjunctive benzodiazepine treatment of hospitalized schizophrenia patients in Asia from 2001 to 2008. Int J Neuropsychopharmacol, 14, 735-745.

Udomratn P., Ng, C., 2008 Outpatients Prescribing Practices in Asian Countries. In Ethno-psychopharmacology: Advances in current practice (eds C. H. Ng, K. M. Lin, B. Singh, et al), pp. 135-143. London: Cambridge University Press. Van Dorn R.A., Swanson, J.W., Swartz, M.S., Elbogen, E.B. (2005) The effects of race and criminal justice involvement on access to atypical antipsychotic medications among persons with schizophrenia. Ment Health Serv Res, 7, 123-134.

Wang Z.M., Zhu, H., Pan, Y.L., Chiu, H.F., Correll, C.U., Ungvari, G.S., Lai, K.Y., Cao, X.L., Li, Y., Zhong, B.L., Zhang, X.Y., Xiang, Y.T. (2014) Electroconvulsive Therapy and Its Association With Demographic and Clinical Characteristics in Chinese Psychiatric Patients. Journal of ECT, Doi: 
10.1097/YCT.0000000000000181.

Weissman E.M. (2002) Antipsychotic prescribing practices in the Veterans Healthcare Administration--New York metropolitan region. Schizophrenia Bulletin, 28, 31-42.

Wheeler A., Humberstone, V., Robinson, E. (2008) Ethnic comparisons of antipsychotic use in schizophrenia. Australian and New Zealand Journal of Psychiatry, 42, 863-873.

Woods S.W. (2003) Chlorpromazine equivalent doses for the newer atypical antipsychotics. Journal of Clinical Psychiatry, 64, 663-667.

World Health Organization (2011) Mental Health Atlas - 2011 country profiles. Geneva, Switzerland: WHO.

Xiang Y.T., Li, Y., Correll, C.U., Ungvari, G.S., Chiu, H.F., Lai, K.Y., Tang, Q.S., Hao, W., Si, T.M., Wang, C.Y., Lee, E.H., He, Y.L., Yang, S.Y., Chong, M.Y., Kua, E.H., Fujii, S., Sim, K., Yong, M.K., Trivedi, J.K., Chung, E.K., Udomratn, P., Chee, K.Y., Sartorius, N., Tan, C.H., Shinfuku, N. (2014) Common use of high doses of antipsychotic medications in older Asian patients with schizophrenia (2001-2009). International Journal of Geriatric Psychiatry, 29, 359-366.

Xiang Y.T., Ma, X., Cai, Z.J., Li, S.R., Xiang, Y.Q., Guo, H.L., Hou, Y.Z., Li, Z.B., Li, Z.J., Tao, Y.F., Dang, W.M., Wu, X.M., Deng, J., Lai, K.Y., Ungvari, G.S. (2008) Prevalence and socio-demographic correlates of schizophrenia in Beijing, China. Schizophrenia Research, 102, 270-277. 
Xiang Y.T., Weng, Y.Z., Leung, C.M., Tang, W.K., Ungvari, G.S. (2007a) Clinical and social determinants of long-term use of benzodiazepines and its impact on quality of life of Chinese schizophrenia patients. Pharmacopsychiatry, 40, 269-274.

Xiang Y.T., Weng, Y.Z., Leung, C.M., Tang, W.K., Ungvari, G.S. (2007b) Clinical correlates of clozapine prescription for schizophrenia in China. Hum Psychopharmacol, 22, 17-25.

Xiang Y.T., Yu, X., Sartorius, N., Ungvari, G.S., Chiu, H.F. (2012) Mental health in China: challenges and progress. Lancet, 380, 1715-1716.

Zhang G.P., Wang, C.Y. (2001) The one-day survey on psychotropic drugs use in 788 psychotic inpatients in Beijing Anding Hospital (in Chinese). The Chinese J ournal of Clinical Pharmacology, 17, 287-289. 
Table 1. Socio-demographic and clinical characteristics and psychotropic drug prescription in China and Japan in 2001, 2004, and 2009

\begin{tabular}{|c|c|c|c|c|c|c|c|c|c|c|c|c|c|c|c|c|}
\hline$\sqrt{2 x}$ & \multicolumn{8}{|c|}{ China } & \multicolumn{8}{|c|}{ Japan } \\
\hline Survey time & \multicolumn{2}{|c|}{2001} & \multicolumn{2}{|c|}{2004} & \multicolumn{2}{|c|}{2009} & \multicolumn{2}{|c|}{ Total } & \multicolumn{2}{|c|}{2001} & \multicolumn{2}{|c|}{2004} & \multicolumn{2}{|c|}{2009} & \multicolumn{2}{|c|}{ Total } \\
\hline Patients (n) & & & & & & & & & & & & & & & 17 & \\
\hline 2 & Mean & SD & Mean & SD & Mean & SD & Mean & SD & Mean & SD & Mean & SD & Mean & SD & Mean & SD \\
\hline Age (years) & 38.5 & 12.9 & 38.8 & 14.6 & 42.4 & 13.1 & 39.6 & 13.6 & 52.8 & 13.5 & 52.1 & 15.0 & 51.5 & 15.4 & $52.2^{* *}$ & 14.6 \\
\hline $\begin{array}{l}\text { Length of current } \\
\text { hospitalizations (days) }\end{array}$ & 52.1 & 95.0 & 43.1 & 109.9 & 85.9 & 183.7 & 57.5 & 128.5 & 540.5 & 583.7 & 411.8 & 572.1 & 373.2 & 524.5 & $449.6^{* *}$ & 568.2 \\
\hline & & & & & & & & & & & & & & & & \\
\hline & $\mathrm{N}$ & $\%$ & $\mathrm{~N}$ & $\%$ & $\mathrm{~N}$ & $\%$ & $\mathrm{~N}$ & $\%$ & $\mathrm{~N}$ & $\%$ & $\mathrm{~N}$ & $\%$ & $\mathrm{~N}$ & $\%$ & $\mathrm{~N}$ & $\%$ \\
\hline 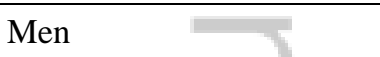 & 311 & 50.9 & 261 & 51.8 & 284 & 69.4 & 856 & 56.2 & 366 & 58.4 & 336 & 57.6 & 284 & 55.3 & 986 & 57.2 \\
\hline First admission & 187 & 30.6 & 177 & 35.1 & 104 & 25.4 & 468 & 30.7 & 126 & 20.1 & 106 & 18.2 & 102 & 19.8 & $334^{* *}$ & 19.4 \\
\hline Positive symptoms & 372 & 60.9 & 329 & 65.3 & 213 & 52.1 & 914 & 60.0 & 396 & 63.2 & 417 & 71.5 & 415 & 80.7 & $1228^{* *}$ & 71.2 \\
\hline Negative symptoms & 300 & 49.1 & 365 & 72.4 & 289 & 70.7 & 954 & 62.6 & 466 & 74.3 & 386 & 66.2 & 305 & 59.3 & $67.1^{* *}$ & 67.1 \\
\hline Acute EPS & 115 & 18.8 & 58 & 11.5 & 82 & 20.0 & 255 & 16.7 & 180 & 28.7 & 192 & 32.9 & 125 & 24.3 & $497^{* *}$ & 28.8 \\
\hline Tardive dyskinesia & 19 & 3.1 & 7 & 1.4 & 11 & 2.7 & 37 & 2.4 & 42 & 6.7 & 45 & 7.7 & 25 & 4.9 & $112^{* *}$ & 6.5 \\
\hline$>/=1000 \mathrm{mg} / \mathrm{d}$ in CPZeq & 46 & 7.5 & 39 & 7.7 & 48 & 11.7 & 133 & 8.7 & 200 & 31.9 & 111 & 19.0 & 95 & 18.5 & $406^{* *}$ & 23.5 \\
\hline 2 & 289 & 47.3 & 177 & 35.1 & 99 & 24.2 & 565 & 37.1 & 548 & 87.4 & 388 & 66.6 & 272 & 52.9 & $1208^{* *}$ & 70.1 \\
\hline SGA except clozapine & 148 & 24.2 & 178 & 35.3 & 234 & 57.2 & 560 & 36.7 & 316 & 50.4 & 441 & 75.6 & 437 & 85.0 & $1194^{* *}$ & 69.3 \\
\hline Clozapine & 243 & 39.8 & 203 & 40.3 & 109 & 26.7 & 555 & 36.4 & 0 & 0 & 0 & 0 & 0 & 0 & $0^{* *}$ & 0 \\
\hline APP & 154 & 25.2 & 120 & 23.8 & 147 & 35.9 & 421 & 27.6 & 493 & 78.6 & 391 & 67.1 & 313 & 60.9 & $1197^{* *}$ & 69.4 \\
\hline Benzodiazepines & 44 & 7.2 & 125 & 24.8 & 68 & 16.6 & 237 & 15.6 & 141 & 22.5 & 148 & 25.4 & 112 & 21.8 & $401^{* *}$ & 23.3 \\
\hline Mood stabilizers & 152 & 24.9 & 117 & 23.2 & 125 & 30.6 & 394 & 25.9 & 223 & 35.6 & 214 & 36.7 & 190 & 37.0 & $627^{* *}$ & 36.4 \\
\hline Antidepressants & 29 & 4.7 & 29 & 5.8 & 33 & 8.1 & 91 & 6.0 & 14 & 2.2 & 13 & 2.2 & 14 & 2.7 & $41^{* *}$ & 2.4 \\
\hline Electroconvulsive therapy & 36 & 5.9 & 56 & 11.1 & 62 & 15.2 & 154 & 10.1 & 1 & 0.2 & 4 & 0.7 & 9 & 1.8 & $14^{* *}$ & 0.8 \\
\hline
\end{tabular}

This article is protected by copyright. All rights reserved. 
Univariate comparison between China and Japan: *<0.05; **<0.01; APP=antipsychotic polypharmacy; CPZeq=chlorpromazine equivalents; EPS=extrapyramidal symptoms; FGA=first-generation antipsychotic; SGA=second-generation antipsychotic

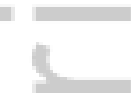

Table 2. Multiple logistic regression analyses of the difference between China and Japan on psychotropic drug prescription in the pooled sample $(\mathrm{n}=3,248)$

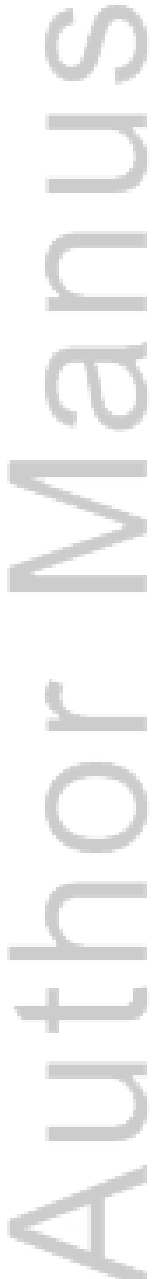

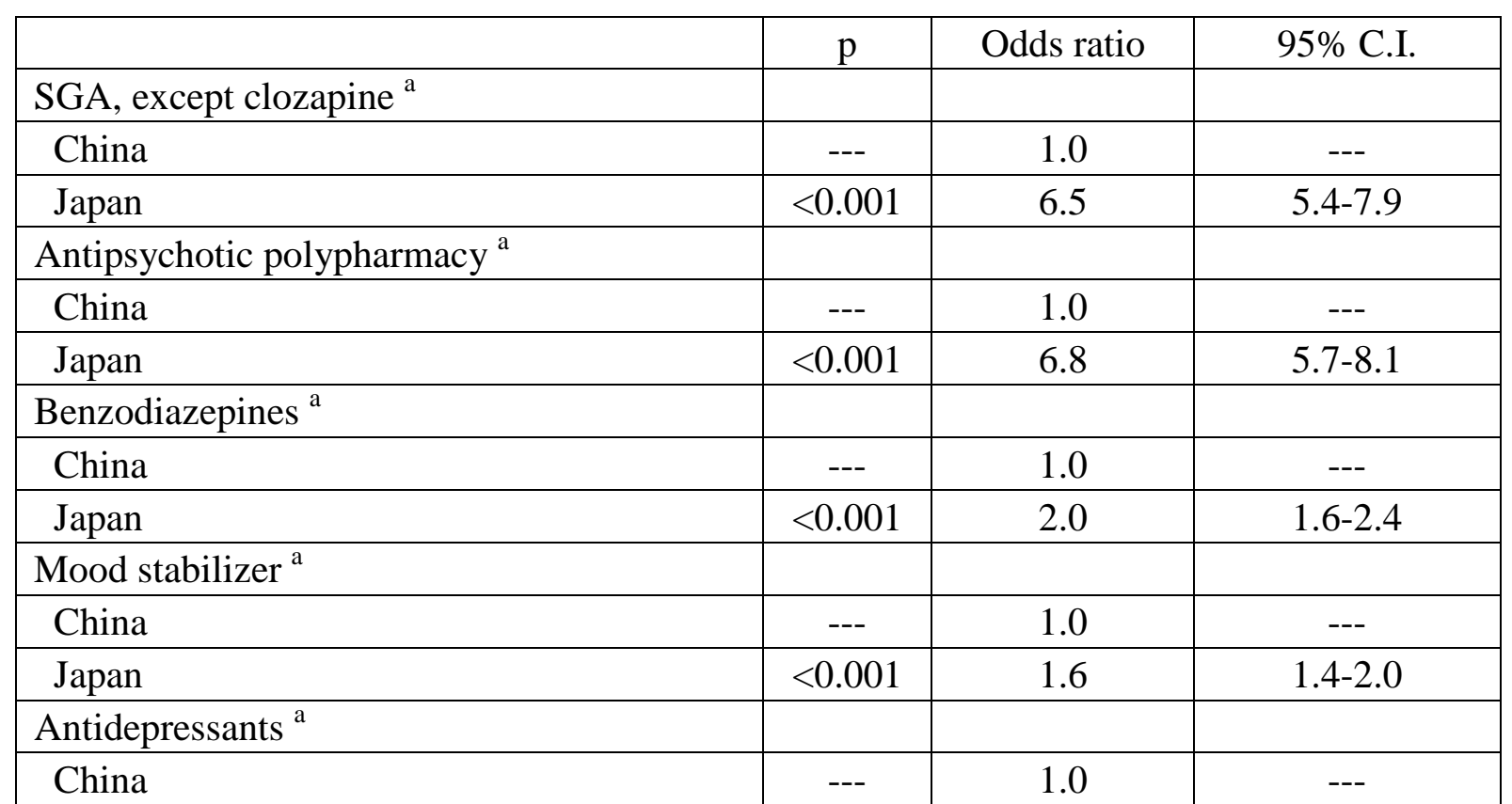




\begin{tabular}{|c|c|c|c|c|}
\hline & Japan & 0.02 & 0.5 & $0.3-0.7$ \\
\hline & $\begin{array}{l}\text { High dose antipsychotics }(>/=1000 \mathrm{mg} / \mathrm{d} \text { in } \\
\text { CPZeq) }^{\text {a }}\end{array}$ & & & \\
\hline & China & --- & 1.0 & --- \\
\hline & Japan & $<0.001$ & 3.9 & $3.1-5.0$ \\
\hline & Electroconvulsive therapy ${ }^{\mathrm{a}}$ & & & \\
\hline & China & --- & 1.0 & --- \\
\hline & Japan & $<0.001$ & 0.07 & 0.04-0.1 \\
\hline
\end{tabular}

a: after controlling for study time, age, first admission, psychopathology, acute EPS and tardive dyskinesia; CPZeq=chlorpromazine equivalents; SGA=second-generation antipsychotic

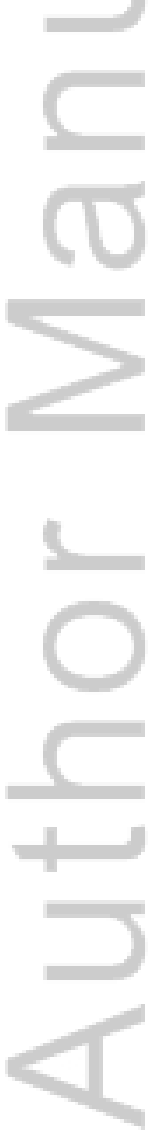




\section{University Library}

\section{- M M N E R VA A gateway to Melbourne's research publications}

Minerva Access is the Institutional Repository of The University of Melbourne

Author/s:

Xiang, Y-T;Kato, TA;Kishimoto, T;Ungvari, GS;Chiu, HFK;Si, T-M;Yang, S-Y;Fujii, S;Ng, $\mathrm{CH}$;Shinfuku, N

Title:

Comparison of treatment patterns in schizophrenia between China and Japan (2001-2009)

Date:

2017-12-01

Citation:

Xiang, Y. -T., Kato, T. A., Kishimoto, T., Ungvari, G. S., Chiu, H. F. K., Si, T. -M., Yang, S. -Y., Fujii, S., Ng, C. H. \& Shinfuku, N. (2017). Comparison of treatment patterns in schizophrenia between China and Japan (2001-2009). ASIA-PACIFIC PSYCHIATRY, 9 (4), https://doi.org/10.1111/appy. 12277.

Persistent Link:

http://hdl.handle.net/11343/292458 